Original Research Paper

\title{
A Hybrid Decision-Making Model for Maintenance Prioritization in Health Care Systems
}

\author{
Hassana Mahfoud, Abdellah El Barkany and Ahmed El Biyaali \\ Faculty of Sciences and Techniques, Mechanical Engineering Laboratory, \\ Sidi Mohammed Ben Abdellah University, B.P. 2202-Route d'Imouzzer-Fez, Morocco
}

\author{
Article history \\ Received: 03-03-2016 \\ Revised: 02-04-2016 \\ Accepted: 27-04-2016 \\ Corresponding Author: \\ Hassana Mahfoud \\ Faculty of Sciences and \\ Techniques, Mechanical \\ Engineering Laboratory, Sidi \\ Mohammed Ben Abdellah \\ University, B.P. 2202-Route \\ d'Imouzzer-Fes, Morocco \\ Email: Hassana.mahfoud@usmba.ac.ma
}

\begin{abstract}
Clinical engineering departments have to establish and continuously regulate a Medical Equipment Management Program (MEMP) to ensure a high reliability and safety of their critical medical devices. Asset criticality assessment is an essential element of reliability centered maintenance and risk-based maintenance, especially when enormous various devices exist and the worst failure consequences are not evident. This paper presents a new risk-based prioritization framework for maintenance decisions. We propose a Multi-Expert Multi-Criteria decision making (MEMC) model to classify medical devices according to their criticality and we describe how obtained scores are used to set up guidelines for appropriate maintenance strategies.
\end{abstract}

Keywords: Medical Devices, MEM Program, Risk-Based Prioritization, Criticality Assessment, MEMC Decision Making and Maintenance Strategies

\section{Introduction}

Medical devices are over 5000 different types used in all aspects of healthcare services, ranging from a simple tongue depressor to a sophisticated pacemaker (Dhillon, 2000). According to Jamshidi et al. (2014) on average, hospitals acquire about 15 to 20 pieces of medical equipment for each staffed bed, that interprets a capital investment of around 200-400 thousand US\$/staffed bed. The same study (Jamshidi et al., 2014) indicates that maintenance costs represent nearly $1 \%$ of the total hospital budget, so hospitals use up around 8 million US\$/year. As well as high maintenance costs, statistics ensued by Joint Commission (TJC) highlight that medical equipment is often engaged in patient incidents that lead to grave injuries and deaths (Wang, 2012). In fact, inadequate maintenance and performance degradation of medical devices create an unacceptable risk level. Hazards associated with medical devices utilization and maintenance is currently the key issue for healthcare organizations (Florence and Calil, 2007).

Accordingly, clinical engineers have been developing Medical Equipment Management Programs (MEMP) to reduce risks and improve the safety of medical equipment in support of patient care. These programs appeal for an effective and efficient framework to prioritize medical devices for appropriate maintenance decisions based on key criteria (Wang, 2012). The boosted complexity of the organizational context resulted in numerous variables to consider among numerous alternatives. Therefore, healthcare professionals face a Multicriteria Decision-Making problem (MCDM). Many models have been proposed in the literature for this reason and are currently in use (Zardari et al., 2014). However, in most of them, important operational conditions criteria are overlooked and equal risk levels are assigned to similar equipments, the thing that could lead to inaccurate results and misclassified devices. Besides, group decision problems involving multi-actors, each with different skills, experience and knowledge about the problem, are often under addressed. Actually, to synthesize multi-expert decision problems, the competence of each actor has to be taken into account (Canfora and Troiano, 2004) in order to maintain the model transparency and verifiability.

This paper presents a Hybrid Group Decision Making (HGDM) model to the medical devices classification problem within Risk-Based Maintenance (RBM) framework. This approach first prioritizes medical equipments in a group decision environment based on their criticality, using a hybrid (AHP-PROMETHE) method and then proposes a diagram for deciding on adequate maintenance policy for each device. One of the benefits of the approach is that the AHP's level of subjectivity is sensibly 
reduced since the group model utilizes performancebased calibration of the experts.

The objectives of this study are: (1) To propose a structured judgment expert methodology and derive voting power used for aggregating group opinions. (2) To reassess key criteria and sub-criteria affecting medical devices risk scores and establish their weights using group AHP method. (3) To propose a maintenance selection diagram based on scores obtained by group PROMETHEE outranking technique. Finally, the proposed framework is illustrated by a case study in a Moroccan hospital.

\section{Literature Review}

Medical devices prioritization has been a very important issue for healthcare organizations for years. Researchers used different approaches to classifying equipments for maintenance decisions. For example, Wang and Levenson (2000) presented Equipment Management Rating (EMR) index computing a simple arithmetic average of four criteria. Wang and rice (2003) discussed a simplified gradient risk sampling plan that includes traditionally excluded equipment. Youssef and Hyman (2009) suggested a classification model based on devices technical complexity and use complexity ranking. Taghipour et al. (2011) debated that although the risk is an important criterion, other factors should be taken into accounts such as utilization rate and mission criticality. To overcome this problem they proposed a Simple Additive Weighting (SAW) of six criteria assessed using the Analytical Hierarchical Process (AHP) method.

Multi-objective Decision Making is a renowned branch of decision making. It is a part of a general class of Operations Research (OR) domain which deals with decision problems under the presence of a number of decision criteria/alternatives (Triantaphyllou et al., 1998). It involves a set of approaches, found in the literature with different names, like Multi-Criteria Decision Making (MCDM) and Multi-Attribute Decision Making (MADM) (Gonçalves and Belderrain, 2012). AHP, the theory of measurement through expert judgment pairwise comparison (Saaty, 2008), is the most popular method used to derive criteria weights (Guneri et al., 2015). Among most of the Multicriteria Decision Making (MCDM), it has the advantage of being easy to use, scalable, hierarchy structure adjusted to many sized problems and it's not data intensive (Velasquez and Hester, 2013). In addition, many types of research consider AHP to be well-matched for group decision making due to its role as an aggregating mechanism (Peniwati, 2007; Lai et al., 2002). However, the application of AHP alone is unwieldy with the augmented number of evaluation criteria and laborious pairwise comparisons for all alternatives with respect to each criterion.

Recently, Lhomme et al. (2013) presented a condition based model (MACE), summing up four criteria determined by users and five others assessed by biomedical maintenance service. Simple additive weighted scores or SAW is intuitive and easy but has many specific disadvantages (Velasquez and Hester, 2013): The estimates yielded do not always reflect the real situation and may not be logical (Podvezko, 2011). To cover this shortcoming, Tawfik et al. (2013) and Jamshidi et al. (2015) developed a fuzzy multicriteria decision tool based on fuzzy theory, the extension of classical set theory (Balmat et al., 2011) which allows uncertain inputs and insufficient information. Nevertheless, fuzzy systems can sometimes be difficult to develop and require numerous simulations before implementation. Moreover, Saaty and Tran (2007) demonstrated that Fuzzification approach achieves quantitativeness, but it's ineffective and capable of creating more uncertainties.

Zardari et al. (2014) gives an overview of the best known outranking techniques helping to solve the shortage of AHP method and providing a specific preference function to select constrained alternatives. Developed by (Brans and Vincke, 1985), PROMETHEE has found its application in several domains (Gonçalves and Belderrain, 2012; Taha and Rostam, 2012; Murali et al., 2014) owing to its many advantages. In fact, using a preference function with its thresholds to evaluate each criterion leads to a more reliable understanding of perception differences among the decision-makers at assessing each alternative. Though, it doesn't provide a clear method by which to assign weights, the reason of its combination with others subjective weighing methods.

In multi-expert decision aiding environments, we often have to deal with different judgments, the different importance of experts, censoring data, unexpressed belief and experts who are not fully confident with their opinions (Canfora and Troiano, 2004; Firmino and Droguett, 2015). All these factors make the problem more difficult to handle and run the risk of less transparent model logic. In such cases, Expert judgment elicitation techniques have proven to be a powerful tool to evaluate experts in order to quantify models in situations when enough information proved to be scarce (Hora, 2009; La Cruz, 2009). Dawotola (2012) used a classical model proposed by (Cooke and Goossens, 2004) to rank pipelines segments on increasing level of risk when historical data are not available or insufficient. Burgman et al. (2006) review the biases and heuristics in expert judgment and illustrate methods for elicitation probabilities and scoring rules for evaluating experts. Flander et al. (2012) uses probability bounds 
analysis to supplement expert elicitation by framing risk problems in heuristic terms. In healthcare domain, hardly any researches have pointed out the multi-expert problem. Jamshidi et al. (2015) tried to define a voting power index based on expert's experience, however, assigned weights are direct and baseless.

Therefore, to overcome all of the above-mentioned weaknesses in existing prioritization models in healthcare systems, we suggest a comprehensive risk-based maintenance framework for prioritization of medical devices, considering the case of multi-expert environment where the level of agreement of experts, such as their importance and confidence are necessary in order to maintain the model transparency and verifiability.

\section{Proposed Model}

In this study, we present a hybrid approach of Expert judgment, AHP and PROMETHEE to solve the multicriteria prioritization problem. The proposed model is regarded as a rational agent capable of aggregating different sources of information to handle the same multi-criteria decision making problem. The structure of this approach is illustrated in Fig. 1. A pool of clinical engineering experts (DMs) is solicited to give opinions about the prioritization problem, which is transformed to a summary of scores for determined criteria and alternatives. This is the required data entered into the hybrid program. Based on logical and mathematical assumptions, criteria are weighted and the final ranking of alternatives is done, followed by analysis of results. The approval of the outcome and final decision is made by decision makers.

This model is executed through three main stages presented in Fig. 3.

\section{Expert Judgment Elicitation}

The expert selection process hunts to create a set of experts who represent a well-adjusted range with respect to their experience and scientific expertise to the topic. We followed a formal method for deriving the requisite weights for this group of experts. It is a structured expert judgment elicitation approach; that entails treating expert judgments as a scientific data in a proper decision process.

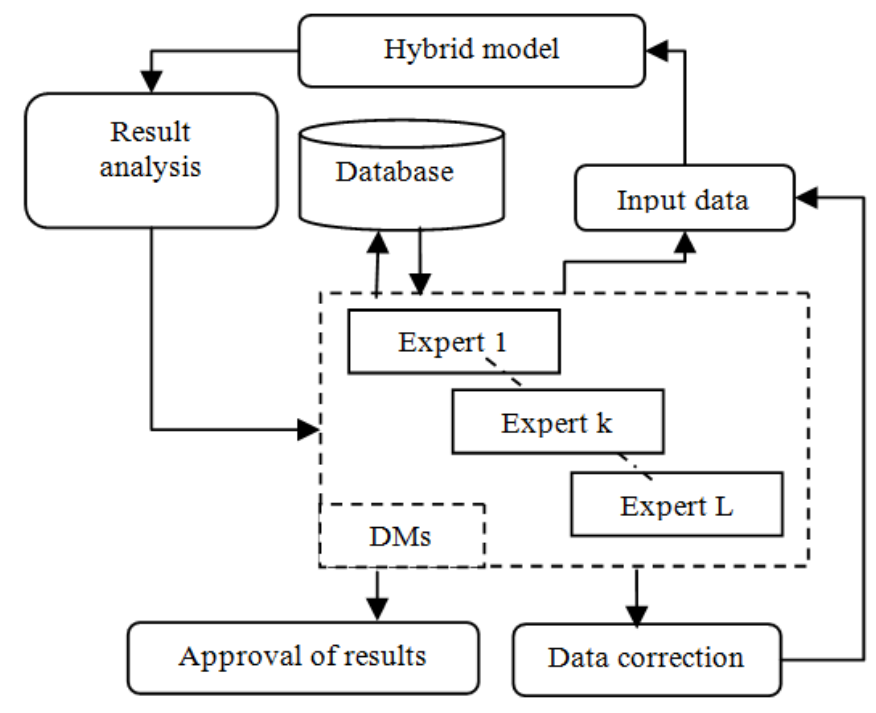

Fig. 1. Conceptual frame of the proposed model



Fig. 2. Hierarchy structure 


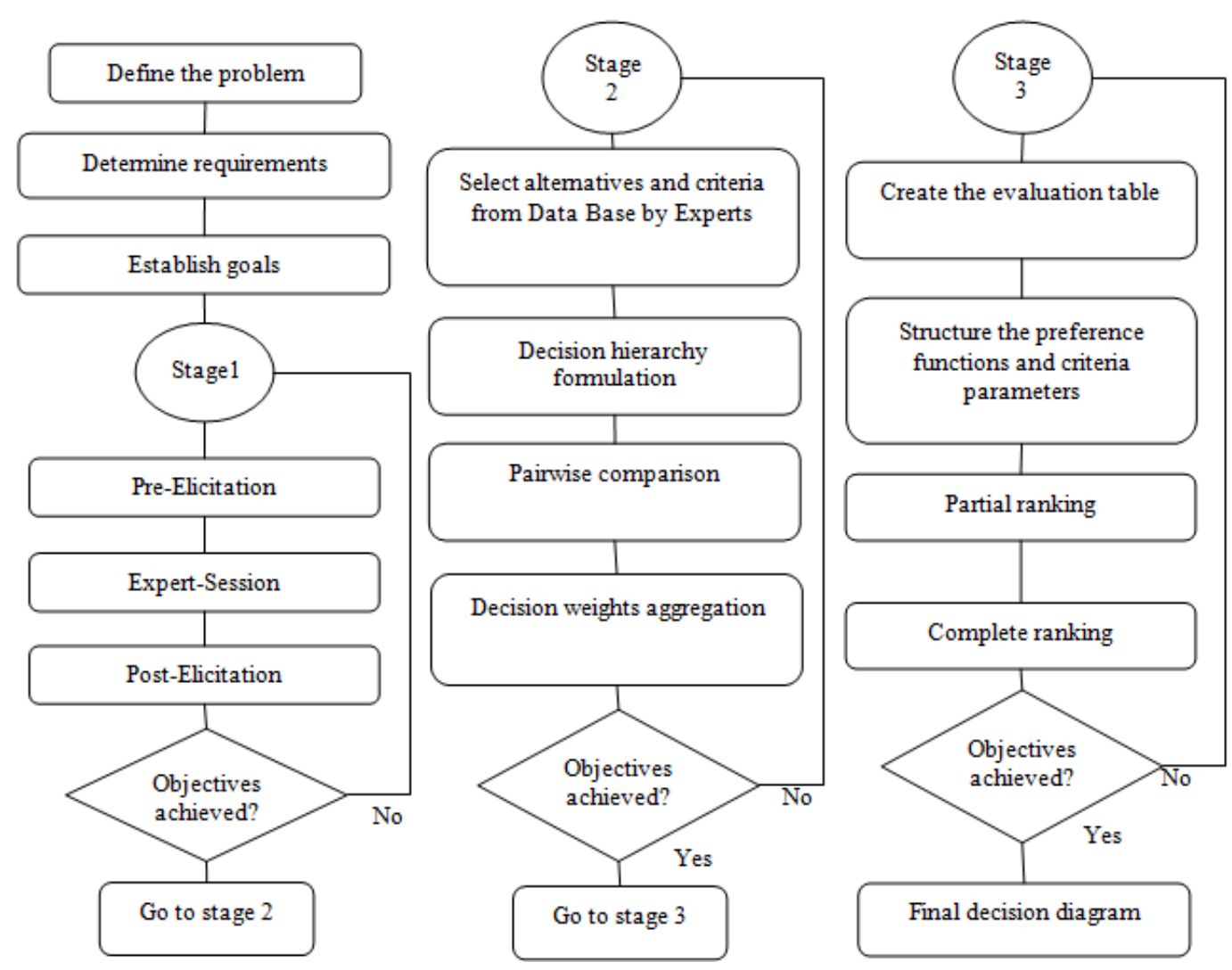

Fig. 3. Flow chart of the proposed model

\section{Pre-Elicitation}

This step includes the definition of the problem (Dawotola, 2012), spotting target variables, deciding format of the elicitation procedure (interview, questionnaire), creating documentation (including prospects and intended use of results) and finally the identification of core expertise $(e 1, . ., e k, . ., e L)$ for $L \geq 2$.

\section{Elicitation: Expert Session}

This stage consists on calibrating experts based on how good they estimate uncertainty over a value that is unknown to them. For this goal, the experts are asked to assess $\mathrm{w}$ calibration variables $\left(x_{1}, . ., x_{\mathrm{i}}, . ., x_{w}\right)$, for which realizations $\left(d_{1}, . . d_{i}, . . d_{w}\right)$ are only known to the analyst conducting the session (La Cruz, 2009).

\section{Post-Elicitation}

In this final step, experts' assessments are combined to estimate probabilities scores $\left(S_{k}\right)$ and derive voting power $\left(V_{k}\right)$ of each expert (Fülöp, 2005). Inspired by (Wallsten et al., 1997) on how to evaluate and combine subjective probability estimates, we propose:

$$
S_{k}=\frac{1}{w} \sum_{i=1}^{w}(x i-d i)^{2}
$$

The lower the probability score, the better the overall accuracy (the perfect score is 0 ):

$$
V_{k}=\frac{1}{L-1}\left(1-\frac{S_{k}}{\sum_{k=1}^{L} S_{k}}\right)
$$

The voting power is an inversion of probability scores that evaluate the qualification of an expert (Keeney and Raiffa, 1993). This value helps to aggregate the different opinions of experts (Fülöp, 2005).

\section{Criteria Assessment}

\section{Decision Hierarchy Formulation}

All required criteria $\left(C_{1} . ., C_{i} . ., C_{n}\right)$ and alternatives $A_{j}$, $j=1, . ., m$ for the prioritization model are determined at the outset of the AHP process application, Fig. 2.

\section{Decision Weights Aggregation}

Based on pairwise comparison described in $^{13}$, we obtain a decision matrix $D^{k}=\left(d_{i j}^{k}\right), i j=1, \ldots, n$ for each expert $k$. The combined matrix $C=\left(c_{i j}\right), i j=1, \ldots, n$ of the group is calculated using a generalized mean of the corresponding entries $d_{i j}^{k}$ considering the voting power of each expert $V_{k}$ : 
$c_{i j}=\prod_{k=1}^{L} d_{i j}^{V_{k}} / \sum_{k=1}^{L} V_{k}$

The matrix $C$ is then multiplied by a vector of weights:

$w=\left[w_{1}, . ., w_{i}, . . w_{n}\right]^{T}: C \times w=n w$

where, $w$ is the eigenvector of $C$. It is obtained by solving:

$$
C w=\lambda_{\max } w
$$

where, $\lambda_{\max }$ is the principle eigenvalue of $C$.

The consistency index $C I$ indicates to what extent the subject actual opinion is captured:

$$
C I=\frac{\lambda_{\max }-n}{n-1}
$$

The random index $R I$ represents the consistency of a randomly generated reciprocal matrix with reciprocal forces. Then the matrix consistency ratio $C R$ is derived:

$$
C R=\frac{C I}{R I}
$$

If this value $(C R)$ is significantly small, carefully specified to be $10 \%$ or less, the weights estimate is accepted.

\section{Ranking Alternatives}

Once criteria's weights $C_{i}\left(w_{i}\right), i=1, . ., n$ are calculated and alternatives $A_{j}, j=1, . ., m$ are determined. The evaluation of alternatives performance against each criterion is completed by the determined experts $\left(e_{1}, .\right.$. , $\left.e_{k}, . ., e_{L}\right)$. We obtain an evaluation matrix $E^{k}=\left(x_{i j}^{k}\right), i=$ $1, \ldots, n ; j=1, \ldots, m$.

The combined matrix $A=\left(\dot{x}_{i j}\right), i=1, \ldots, n ; j=1, \ldots, m$. of the group is calculated using a generalized mean of the corresponding entries $x_{i j}^{k}$ considering the voting power of each expert $V_{k}$ :

$$
\dot{x}_{i j}=\prod_{k=1}^{L} x_{i j}^{V_{k}} / \sum_{k=1}^{L} V_{k}
$$

The starting point of the outranking method is the weighted decision matrix: $A\left(\dot{x}_{i j}\right) i=1, \ldots, n ; j=1, \ldots, m$ :

$$
A=\left[\begin{array}{ccc}
\dot{x}_{11} & \ldots & \dot{x}_{1 n} \\
\vdots & \dot{x}_{i j} & \vdots \\
\dot{x}_{m 1} & \ldots & \dot{x}_{m n}
\end{array}\right]
$$

PROMETHEE method is based on a preference function $P$ representing the degree of preference of alternative $\dot{x}_{j}$ over $\dot{x}_{p}$ for criterion $c_{i}$. We consider a degree in normalized form:

$P_{i}\left(\dot{x}_{j}, \dot{x}_{p}\right)=\left\{\begin{array}{l}0, \text { if } d \leq 0 \\ 1, \text { if } d>0\end{array} ; d=\dot{x}_{j}-\dot{x}_{p}\right.$

PROMETHEE I and PROMETHEE II are two techniques used for solving the outranking problem:

\section{Partial Outranking}

In PROMETHEE I, a multicriteria preference index $\pi$ of $\dot{x}_{j}$ over $\dot{x}_{p}$ is defined considering all criteria $C_{i}\left(w_{i}\right), i=1, . ., n$ :

$$
\pi\left(\dot{x}_{j}, \dot{x}_{p}\right)=\sum_{i=1}^{n} w_{i} P_{i}\left(\dot{x}_{j}, \dot{x}_{p}\right) ; d=\dot{x}_{j}-\dot{x}_{p}
$$

The partial ranking is based on the following priority flows:

Outgoing flow:

$\varphi^{+}\left(\dot{x}_{j}\right)=\frac{1}{m-1} \sum_{p=1}^{m} \pi\left(\dot{x}_{j}, \dot{x}_{p}\right)$

Incoming flow:

$\varphi^{-}\left(\dot{x}_{j}\right)=\frac{1}{m-1} \sum_{p=1}^{m} \pi\left(\dot{x}_{p}, \dot{x}_{j}\right)$

\section{Complete Ranking}

Preventing any incomparability, the net outranking flow is then calculated according to PROMETHEE II:

$\varphi\left(\dot{x}_{j}\right)=\varphi^{+}\left(\dot{x}_{j}\right)-\varphi^{-}\left(\dot{x}_{j}\right)$

The net outranking flow is a number between -1 and 1. The alternative $\dot{x}_{j}$ is preferred to $\dot{x}_{p}$ if $\varphi\left(\dot{x}_{j}\right)>\varphi\left(\dot{x}_{p}\right)$ and they are indifferent when $\varphi\left(\dot{x}_{j}\right)=\varphi\left(\dot{x}_{p}\right)$.

\section{Classification and Maintenance Strategies Decision}

As it has been noted, the presented model prioritizes equipments according to their criticality assessment. Given such a model, healthcare organizations could focus their maintenance efforts on the most significant devices.

According to the criticality level of the evaluated equipment, four maintenance policies are defined: In Corrective Maintenance (CM), devices placed in discarded zone of criticality are just run until they break down. 


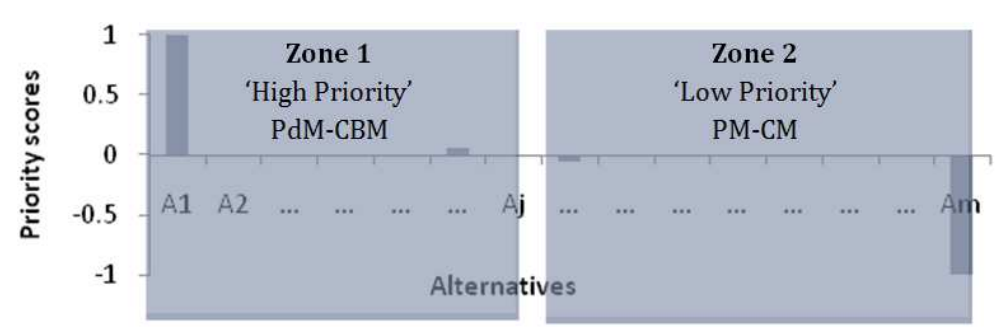

Fig. 4. Maintenance classification diagram

Time-based Preventive Maintenance (PM) compels a periodical maintenance tasks for low critical devices. Proactive $(\mathrm{PdM})$ and Condition-Based Maintenance (CBM) are recommended for high critical devices. These strategies use real-time data to predict failures and optimize maintenance practices.

To prioritize maintenance decisions, we propose a diagram based on criticality scores $-1 \leq \varphi\left(\dot{x}_{j}\right) \leq 1$ achieved by the third step of our approach. Figure 4 shows two zones: Zone2 comprises a 'low priority' area where scores are negatives $-1 \leq \varphi\left(\dot{x}_{j}\right) \leq 0$ and zone1, the 'high priority' area, including high critical devices $0<\varphi\left(\dot{x}_{j}\right)$ entailing a special care to reduce the root causes of this criticality.

\section{Medical Devices Prioritization: Case Study}

We consider medical devices prioritization for maintenance decisions an MCDM problem, seen the number of alternatives and criteria to take into account. The suggested model is applied in a Moroccan 880 bed-hospital, where healthcare professionals usually face this dilemma to prioritize criticality of many types of equipment.

For this purpose, we follow the key steps illustrated in the flow chart above, Fig. 3.

\section{Expert Judgment Elicitation}

In this case study, clinical maintenance experts are selected for expert-session based on their experience, background knowledge and dedication to perform evaluations.

Three Decision Makers (DM) were selected for the second step when they were asked to fill five (calib) calibration variables (e.g., uncertain probabilities about an occurred event in a given department for such devices), the realizations of these questions were then verified and confirmed in the database.

The voting power of the selected $D M S$ is consequently 40, 21 and 39\%, Table 1 .

\section{Criteria Assessment}

\section{Criteria and Sub-Criteria Definition}

There are eight sufficient, efficient and independent criteria affecting the classification decision of medical devices:

\section{C1: Function}

It identifies the main purpose for which a device is used. Medical equipments are categorized under six group dependent on the specific health service delivery (Dhillon, 2011): Imaging and radiation therapy equipment (e.g., ultrasound devices and X-ray machines); Patient diagnostic equipment (e.g., physiologic monitors and endoscopes); life support and therapeutic (e.g., anaesthesia machines, lasers and ventilators); laboratory devices (e.g., centrifuge, lab analyser); patient environmental and transport equipment and other support apparatus.

\section{C2: Recalls and Hazard Alerts}

According to (CL'UE, 2007) Medical devices are classified into four main categories based on criteria like the period of use, invasive or not, the nature and type of invasion, the possibility of reuse or not, diagnostic or therapeutic:

Class I: They are medical devices classified as not critical for patient's life or safety, including namely non-invasive devices and reusable surgical instruments, e.g., electric beds and wheel chairs

Class IIa: It includes devices that represent an acceptable risk level such as diagnostic tools and invasive surgical instruments, e.g., ultrasound equipment, Electrocardiograph and blood pressure

Class IIb: It defines equipment with a higher risk level: Midterm surgical implants, protection devices and active monitoring equipments of a potentially important liquid or dangerous substance within the patient's body. e.g., Hemodialyzers, radiotherapy systems, dialysis machines, incubators, Oximetry, Respirators.

Class III: They are critical medical devices directly involved in patient's life incidents including devices in contact with the central nervous system, heart and blood system, long-term surgical implants e.g., cardiac pacemaker, neuron-endoscopes and contraceptive implants.

\section{C3: Utilization}

Utilization can be defined as a function of usage rate which measures the total hours a medical asset is used on 
average in a hospital and the number of patients served by unit time (Jamshidi et al., 2015). This indicator is noteworthy since medical devices are used with different intensity, e.g., defibrillators aren't operated as frequently as operating devices. It's a significant factor influencing equipment deterioration.

\section{C4: Redundancy}

In order to ensure a specific patient safety level and fixed quality service, every hospital requires a determined equipment redundancy. If there aren't enough available alternative devices, the situation of such asset in the care delivery process turns out to be more critical (Mummolo et al., 2007).

\section{C5: Age}

This ratio is based on the current age of the device and its predictable life span (Taghipour et al., 2011).

\section{C6: Technological Obsolescence}

Medical staff using high technological equipments enhances their performance effectiveness having a noticeable advantage for patient satisfaction (Mummolo et al., 2007).

\section{C7: Maintenance Requirements}

Medical device's maintenance tasks involve two different resources: Materials and skills. Generally in hospitals, maintenance operations demanding high skills and special tools are often outsourced.

\section{C8: Risk}

The risk priority index $\left(R P I_{f}\right)$ of a determined failure mode $(f)$ is a function of three factors: Detectability occurrence and consequences. The risk score $R s$ assigned to a device is an aggregation of all $R P I_{f}$ values of $N_{f}$ failure modes, for Table 5:

$R s=\frac{1}{N_{f}} \sum_{f=1}^{N_{f}} \mathrm{RPI}_{\mathrm{f}}$

Where:
$R P I_{f}=D \times O \times C ; C=S * E c * E v$

\section{Detectability (D)}

It refers to the ability of detection of a potential failure before it occurs. In this case study, we consider the probability of non-detection and the impact of detection method (Jamshidi et al., 2015).

\section{Occurrence $(\mathrm{O})$}

It estimates the frequency of risk for a given device. We use the Mean Time Between Failures (MTBF) as one of frequently used measure in reliability engineering that reflects the chance of failure in a period of time.

\section{Consequences $(C)$}

When a device failure occurs in a hospital, the consequences often display three aspects:

- $\quad$ Patient and operator safety (S): A potential failure in a medical device can result in misdiagnosis, injuries or even death to both patient and operator. So this criterion is considered as the first major consequence

- Economic loss (Ec): It's a combination of maintenance repair costs and the hourly loss linked to delaying treatment. Classification of costs is based on the hospital budget and the device purchase price

- Environmental loss (Ev): This factor is related to the degree of damage caused to the ecosystem due to a medical device failure (Khan and Haddara, 2003)

\section{Decision Weights Calculation}

Once all decision criteria have been defined, their relative importance is estimated using AHP process described in the last section. Table 2 shows a comparison of resulted weights for every expert's opinion $D^{k}=\left(d_{i j}^{k}\right)$, $i j=1, \ldots, n$ and weights calculated from the aggregated pairwise comparison $\mathrm{C}=\left(c_{i j}\right)$ based on Equation 3 .

Table 1. Elicitation results

\begin{tabular}{lllllllll}
\hline Session & Realisation & DM1 & Calib1 & DM2 & Calib2 & DM3 & Calib3 & Variance \\
\hline 1 & $16 \%$ & $20 \%$ & 0,0016 & $10 \%$ & 0,0036 & $20 \%$ & 0,0016 & 0,002 \\
2 & $57 \%$ & $40 \%$ & 0,0289 & $60 \%$ & 0,0009 & $50 \%$ & 0,0049 & 0,008 \\
3 & $10 \%$ & $20 \%$ & 0,01 & $30 \%$ & 0,04 & $20 \%$ & 0,01 & 0,007 \\
4 & $32 \%$ & $30 \%$ & 0,0004 & $20 \%$ & 0,0144 & $50 \%$ & 0,0324 & 0,016 \\
5 & $20 \%$ & $10 \%$ & 0,01 & $50 \%$ & 0,09 & $30 \%$ & 0,01 & 0,029 \\
& Scoring- & Voting power & Expert1 & & Expert2 & & Expert3 & Total \\
& & $\mathrm{S}_{\mathrm{k}}$ & 0,01018 & & 0,02978 & & 0,01178 & 0,05174 \\
& $\mathrm{~S}_{\mathrm{k}} \%$ & $20 \%$ & & $58 \%$ & & $23 \%$ & 1,000 \\
& $\mathrm{~V}_{\mathrm{k}}$ & $40 \%$ & & $21 \%$ & & $39 \%$ & 1,000 \\
\hline
\end{tabular}


Table 2. Decision weights results

\begin{tabular}{lllll}
\hline Criteria & Exp1 $\left(\mathrm{V}_{1}=40 \%\right)$ & Exp2 $\left(\mathrm{V}_{2}=21 \%\right)$ & Exp3 $\left(\mathrm{V}_{3}=39 \%\right)$ & Aggregated weights $(\mathrm{w})$ \\
\hline C1 & $2 \%$ & $2 \%$ & $2 \%$ & $2 \%$ \\
C2 & $16 \%$ & $19 \%$ & $12 \%$ & $15 \%$ \\
C3 & $10 \%$ & $11 \%$ & $4 \%$ & $7 \%$ \\
C4 & $7 \%$ & $6 \%$ & $8 \%$ & $8 \%$ \\
C5 & $7 \%$ & $8 \%$ & $8 \%$ & $8 \%$ \\
C6 & $4 \%$ & $4 \%$ & $4 \%$ & $4 \%$ \\
C7 & $4 \%$ & $4 \%$ & $14 \%$ & $6 \%$ \\
C8 & $49 \%$ & $47 \%$ & $47 \%$ & $50 \%$ \\
$\lambda_{\max }$ & 9,9921 & 10,408 & 9,4921 & 9,2068 \\
CI & 0,2846 & 0,344 & 0,2132 & 0,1724 \\
CR & 0,1878 & 0,1313 & 0,1151 & 0,0966 \\
\hline
\end{tabular}

Table 3. Selected alternatives

\begin{tabular}{ll}
\hline Alternatives & Designation \\
A1 & Radioscopy \\
A2 & Electrosurgical unit \\
A3 & Computed Radiography (FCR) \\
A4 & Electrocardiograph \\
A5 & Ultrasound system \\
A6 & Magnetic resonance imaging \\
A7 & Infusion pump \\
A8 & Automatic X-ray processor \\
A9 & Respirator \\
A10 & CT Scanner \\
\hline
\end{tabular}

Table 4. Criteria Intensity scores

\begin{tabular}{|c|c|c|c|c|c|c|c|c|}
\hline Grade & Intensity & $\begin{array}{l}\text { C1 } \\
\text { Function }\end{array}$ & $\begin{array}{l}\mathrm{C} 2 \\
\text { Recalls and } \\
\text { hazard alerts }\end{array}$ & $\begin{array}{l}\mathrm{C} 3 \\
\text { Utilisation }\end{array}$ & $\begin{array}{l}\text { C4 } \\
\text { Redundancy }\end{array}$ & $\begin{array}{l}\text { C5 } \\
\text { Age }\end{array}$ & $\begin{array}{l}\text { C6 } \\
\text { Technological } \\
\text { obsolescence }\end{array}$ & $\begin{array}{l}\mathrm{C} 7 \\
\text { Maintenance } \\
\text { requirements }\end{array}$ \\
\hline High & 3 & $\begin{array}{l}\text { Life support- } \\
\text { Therapeutic }\end{array}$ & ClassIII & $\begin{array}{l}\text { Usage hours } \\
\text { per day } \geq 12\end{array}$ & $\begin{array}{l}\text { No available } \\
\text { alternatives } \leq 1\end{array}$ & $\begin{array}{l}\text { Age } \geq 90000 \mathrm{~h} \\
\text { of operation }\end{array}$ & Obsolete & $\begin{array}{l}\text { Extensive } \\
\text { maintenance: } \\
\text { Outsourced }\end{array}$ \\
\hline Medium & 2 & $\begin{array}{l}\text { Patient diagnostic- } \\
\text { Analytical }\end{array}$ & ClassII & $\begin{array}{l}8 \leq \text { Usage hours } \\
\text { per day }<12\end{array}$ & $\begin{array}{l}1<\text { Available } \\
\text { alternatives } \leq 4\end{array}$ & $\begin{array}{l}1000 \mathrm{~h} \leq \text { age } \\
<90000 \mathrm{~h}\end{array}$ & Otherwise & $\begin{array}{l}\text { Average } \\
\text { maintenance } \\
\text { requirements }\end{array}$ \\
\hline Low & 1 & Miscellaneous & ClassI & $\begin{array}{l}\text { Usage hours } \\
\text { per day }<8\end{array}$ & $\begin{array}{l}\text { Available } \\
\text { alternatives } \geq 4\end{array}$ & Age $<1000 \mathrm{~h}$ & & $\begin{array}{l}\text { Minimal } \\
\text { maintenance } \\
\text { requirements }\end{array}$ \\
\hline \multicolumn{9}{|l|}{$\mathrm{C} 8$} \\
\hline Grade & Intensity & $\mathrm{D}$ & $\mathrm{O}$ & S & Ec & Ev & & \\
\hline High & 3 & $\begin{array}{l}\text { No inspection } \\
\text { system to detect } \\
\text { failure }\end{array}$ & $\begin{array}{l}\text { MTBF } \leq 3 \\
\text { months }\end{array}$ & Death & Expensive & Harmful & & \\
\hline Medium & 2 & $\begin{array}{l}\text { Incomplete } \\
\text { detection system }\end{array}$ & $\begin{array}{l}3<\mathrm{MTBF} \\
\leq 6 \text { months }\end{array}$ & Injury & Moderate & Acceptable & & \\
\hline Low & 1 & $\begin{array}{l}\text { Automatic } \\
\text { inspection process }\end{array}$ & $\begin{array}{l}\mathrm{MTBF} \geq \\
6 \text { months }\end{array}$ & Misdiagnosis & Acceptable & No effect & & \\
\hline
\end{tabular}

The aggregated combined matrix is perfectly consistent $(C R=9.66<10 \%)$. As a result, the aggregated weights (w) estimate is accepted.

\section{Ranking Alternatives}

Ten medical devices are extracted from the large database of a simplified sample to illustrate the model, Table 3. An evaluation table is created to score the alternatives performance against the eight criteria. Based on Intensity scores defined in Table 4, each expert has to assess the devices with respect to every dimension (matrix $\left.E^{k}=\left(x_{i j}^{k}\right), i=1, \ldots, n ; j=1, \ldots, m\right)$.

Using equation 8 , the desired evaluation table $A\left(\dot{x}_{i j}\right)$ $i=1, \ldots, n ; j=1, \ldots, m$ is then calculated, Table 6 :

$$
\dot{x}_{i j}=x_{i j}^{10,40} * x_{i j}^{20,21} * x_{i j}^{30,39}
$$


Applying PROMETHEE techniques, we get the outranking flows shown in Table 7.

$\varphi^{+}$expresses the power of the alternative's outranking character and $\varphi^{-}$represents the weakness related to its outranked character. Combining these values, $\varphi$ gives the net outranking flow. The obtained results reveal that the magnetic resonance imaging, infusion pump, X-ray processor and CT-Scanner are consecutively the most critical devices.
Comparing expert's individual ranking and the group ranking results, Table 8 , we remark a slight difference in the position of some critical devices: For example $\mathrm{A} 7$ is in the second position according to decision maker 1 and 2. However, the Expert3 assigns this order to the alternative A10. Using group expert method to deal with the difference of opinion, A7 is ranked in the second position.

Table 5. Example of risk assessment for A1

\begin{tabular}{lllllllll}
\hline & $\mathrm{f}$ & $\mathrm{D}$ & $\mathrm{O}$ & $\mathrm{S}$ & $\mathrm{Ec}$ & $\mathrm{Ev}$ & $\mathrm{C}$ & $\mathrm{RPI}$ \\
\hline \multirow{2}{*}{ A1 } & Electronic board & 2 & 2 & 1 & 3 & 2 & 6 & 24 \\
& Power supply & 1 & 3 & 1 & 1 & 1 & 1 \\
& software lock & 2 & 1 & 1 & 2 & 1 & 3 & 2 \\
\end{tabular}

Table 6. Aggregated evaluation table A

\begin{tabular}{|c|c|c|c|c|c|c|c|c|}
\hline & C1 & $\mathrm{C} 2$ & C3 & C4 & $\mathrm{C} 5$ & C6 & $\begin{array}{l}\mathrm{C} 7 \\
5750\end{array}$ & C8 \\
\hline & $1,86 \%$ & $15,33 \%$ & 1,37\% & 1,5 /\% & $7,84 \%$ & 4,33\% & $5, / 5 \%$ & $49,96 \%$ \\
\hline A1 & 2,0 & 2,6 & 2,0 & 2,0 & 2,0 & 1,0 & 2,0 & 11,0 \\
\hline $\mathrm{A} 2$ & 1,0 & 3,0 & 2,0 & 1,0 & 2,0 & 1,0 & 1,3 & 9,3 \\
\hline A3 & 2,0 & 2,0 & 3,0 & 2,0 & 2,0 & 1,0 & 3,0 & 5,9 \\
\hline A4 & 2,0 & 2,0 & 2,6 & 1,0 & 2,0 & 1,0 & 1,0 & 5,7 \\
\hline A5 & 2,0 & 3,0 & 2,0 & 1,0 & 2,0 & 1,3 & 3,0 & 5,8 \\
\hline A6 & 2,0 & 3,0 & 3,0 & 3,0 & 2,0 & 1,0 & 3,0 & 20,4 \\
\hline A7 & 3,0 & 3,0 & 3,0 & 1,0 & 2,0 & 1,0 & 2,2 & 13,0 \\
\hline A8 & 2,0 & 3,0 & 3,0 & 2,0 & 2,0 & 1,0 & 3,0 & 10,7 \\
\hline A9 & 3,0 & 3,0 & 2,0 & 2,0 & 2,0 & 1,0 & 1,0 & 4,8 \\
\hline A10 & 2,0 & 3,0 & 3,0 & 3,0 & 2,0 & 1,0 & 3,0 & 9,0 \\
\hline
\end{tabular}

Table 7. Ranking results

\begin{tabular}{llllllll}
\hline Alternative & $\varphi^{+}$ & & $\varphi^{-}$ & & $\varphi$ & Order \\
\hline A1 & fi1+ & 0,44 & fi1- & 0,5630 & fi1 & $-0,13$ & 5 \\
A2 & fi2+ & 0,37 & fi2- & 0,6305 & fi2 & $-0,26$ & 7 \\
A3 & fi3+ & 0,16 & fi3- & 0,8369 & fi3 & $-0,67$ & 10 \\
A4 & fi4+ & 0,27 & fi4- & 0,7279 & fi4 & $-0,46$ & 9 \\
A5 & fi5+ & 0,35 & fi5- & 0,6548 & fi5 & $-0,31$ & 8 \\
A6 & fi6+ & 0,82 & fi6- & 0,1810 & fi6 & 0,64 & 1 \\
A7 & fi7+ & 0,75 & fi7- & 0,2528 & fi7 & 0,49 & 2 \\
A8 & fi8+ & 0,72 & fi8- & 0,2784 & fi8 & 0,44 & 3 \\
A9 & fi9+ & 0,41 & fi9- & 0,5883 & fi9 & $-0,18$ & 6 \\
A10 & fi10+ & 0,71 & fi10- & 0,2865 & fi10 & 0,43 & 4 \\
\hline
\end{tabular}

Table 8. Ranking results comparison

\begin{tabular}{lllll}
\hline & $\varphi^{\text {EXP1 }}$ & $\varphi^{\text {EXP2 }}$ & $\varphi^{\text {EXP3 }}$ & $\varphi^{\text {Group }}$ \\
\hline A1 & $-0,153$ & $-0,190$ & $-0,127$ & $-0,13$ \\
A2 & $-0,270$ & $-0,277$ & $-0,268$ & $-0,26$ \\
A3 & $-0,667$ & $-0,668$ & $-0,611$ & $-0,67$ \\
A4 & $-0,451$ & $-0,452$ & $-0,502$ & $-0,46$ \\
A5 & $-0,319$ & $-0,309$ & $-0,261$ & $-0,31$ \\
A6 & 0,626 & 0,604 & 0,649 & 0,64 \\
A7 & 0,508 & 0,506 & 0,433 & 0,49 \\
A8 & 0,450 & 0,456 & 0,461 & 0,44 \\
A9 & $-0,163$ & $-0,129$ & $-0,235$ & $-0,18$ \\
A10 & 0,438 & 0,459 & 0,461 & 0,43 \\
\hline
\end{tabular}




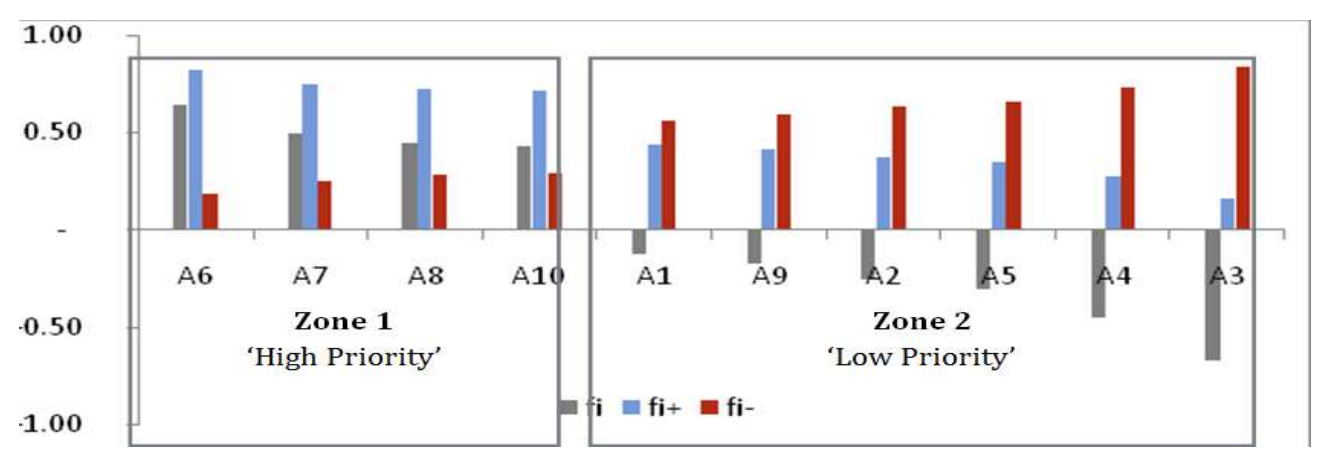

Fig. 5. Maintenance decision diagram

\section{Classification and Maintenance Strategies Decision}

Studying the location of each medical device in the diagram provides directions about maintenance efforts to undertake. As shown in Fig. 5, in our case study, predictive or condition-based maintenance should be adopted for four successive critical equipments: 1magnetic resonance imaging, 2- infusion pump, 3-X-ray processor and 4-CT-Scanner.

In the low priority zone, medical devices are subjected to traditional time-based maintenance. Corrective maintenance is not considered in our case due to the high level of recalls and hazards of the chosen equipments obligating a preventive maintenance policy.

\section{Conclusion}

The main contribution of this study is to propose a multi-expert multi-criteria decision model for medical devices prioritization, a fundamental pillar of every maintenance management program. Effectively, the riskbased prioritization is valuable for maintenance strategies definition, replacement decisions and budget allocation.

In contrast to other existing models, the proposed approach overwhelms the above-mentioned weaknesses, where we often have to deal with different judgments, a variety of criteria and missing data. Facing these problems, our model offers the following features:

- Considering the real situation where decision makers provide opinions with a different degree of confidence and relevance, by affecting voting scores

- Taking into account eight significant criteria in the decision problem and giving a realistic estimate of risk, which combines the assessment of relevant consequences (Safety, Economic and environmental loss) on all failure modes

- PROMETHEE method application brings about a more reliable understanding of perception variation among experts at evaluating each alternative; furthermore, it doesn't allow unacceptable compensation of key disadvantages between criteria
- Using AHP method to compensate the limitation of PROMETHEE by determining weighing values

- Easiness: Classification of maintenance policies based criticality by means of a graphic solution

Finally, a real case study illustrates to any extent the implementation of the proposed framework is efficient in classifying medical devices, improving then the process of maintenance decision making in a multi-expert environment. This model is not limited to the healthcare domain and may be applied in other critical industries by merely changing some dimensions.

\section{Acknowledgement}

A special thank to the clinical engineering department of the Moroccan hospital where we carried out our study.

\section{Author's Contributions}

Hassana Mahfoud: Involvement in analytical work, conception, acquisition of data, analysis, interpretation of the results and presentation.

Abdellah El Barkany: Drafting, reviewing it critically for significant intellectual content and approval of submitted revised versions.

Ahmed El Biyaali: Approval of final proof version.

\section{Ethics}

This article is original and contains unpublished material. The corresponding author confirms that all of the other authors have read and approved the manuscript and no ethical issues involved.

\section{References}

Balmat, J.F., F. Lafont, R. Maifret and N. Pessel, 2011. A decision-making system to maritime risk assessment. Ocean Eng., 38: 171-176. DOI: 10.1016/j.oceaneng.2010.10.012 
Brans, J.P. and P. Vincke, 1985. Note-a preference ranking organisation method: (The PROMETHEE method for multiple criteria decision-making). Manage. Sci., 31: 647-656.

DOI: $10.1287 / \mathrm{mnsc} .31 .6 .647$

Burgman, M., F. Fidler, M. Mcbride, T. Walshe and B. Wintle, 2006. Eliciting expert judgments: Literature review.

Canfora, G. and L. Troiano, 2004. A model for opinion agreement and confidence in multi-expert multicriteria decision making. Mathw. Soft Comput., 11: 67-82.

CL'UE, 2007. Directive 93/42/CEE Relative Aux Dispositifs Médicaux. Conseil de l'Union Européenne. www.legifrance.gouv.fr.

Cooke, R.M. and L.H.J. Goossens, 2004. Expert judgement elicitation for risk assessments of critical infrastructures. J. Risk Res., 7: 643-656.

DOI: $10.1080 / 1366987042000192237$

Dawotola, A.W., 2012. Risk based maintenance of petroleum pipelines.

Dhillon, B.S., 2000. Medical Device Reliability and Associated Areas. 1st Edn., CRC Press, ISBN-10: 1420042238, pp: 264.

Dhillon, B.S., 2011. Medical equipment reliability: A review, analysis methods and improvement strategies. Int. J. Reliab. Qual. Saf. Eng., 18: 391-403. DOI: $10.1142 / \mathrm{S} 0218539311004317$

Firmino, P.R.A. and E.L. Droguett, 2015. An expert opinion elicitation method based on binary search and Bayesian intervals. Int. J. Risk Assess. Manage., 18: 336-362. DOI: 10.1504/IJRAM.2015.071224

Flander, L., W. Dixon, M. McBride and M. Burgman, 2012. Facilitated expert judgment of environmental risks: Acquiring and analysing imprecise data. Int. J. Risk Assess. Manage., 16: 199-212.

DOI: 10.1504/IJRAM.2012.051259

Florence, G. and S.J. Calil, 2007. Risk classification of medical equipment in alert states. J. Clin. Eng., 32: 79-84. DOI: 10.1097/01.JCE.0000269278.08840.75

Fülöp, J., 2005. Introduction to decision making methods. Proceedings of the BDEI-3 Workshop, (BDEI' 05), Citeseer, Washington.

Gonçalves, T.J.M. and M.C.N. Belderrain, 2012. Performance evaluation with PROMETHEE GDSS and GAIA: A study on the ITA-SAT satellite project. J. Aerosp. Technol. Manage., 4: 381-392. DOI: $10.5028 /$ jatm. 2012.04033411

Guneri, A.F., M. Gul and S. Ozgurler, 2015. A fuzzy AHP methodology for selection of risk assessment methods in occupational safety. Int. J. Risk Assess. Manage., 18: 319-335.

DOI: 10.1504/IJRAM.2015.071222

Hora, S.C., 2009. Expert judgment in risk analysis. University of Hawaii at Hilo.
Jamshidi, A., S.A. Rahimi, D. Ait-kadi and A. Ruiz, 2015. A comprehensive fuzzy risk-based maintenance framework for prioritization of medical devices. Applied Soft Comput., 32: 322-334. DOI: $10.1016 /$ j.asoc.2015.03.054

Jamshidi, A., S.A. Rahimi, D. Ait-kadi and M. Engineering, 2014. Medical devices inspection and maintenance-a literature review. Proceedings of the IIE Annual Conference, (AC' 14), Bartolome, Angel Ruiz.

Keeney, R.L. and H. Raiffa, 1993. Decisions with Multiple Objectives: Preferences and Value TradeOffs. 1st Edn., Cambridge University Press, Cambridge, ISBN-10: 0521438837, pp: 569.

Khan, F.I. and M.M. Haddara, 2003. Risk-Based Maintenance (RBM): A quantitative approach for maintenance/inspection scheduling and planning. J. Loss. Prev. Process Ind., 16: 561-573.

DOI: 10.1016/j.jlp.2003.08.011

La Cruz, J.L.D., 2009. Expert session and expert judgement analysis. Deltares.

Lai, V.S., B.K. Wong and W. Cheung, 2002. Group decision making in a multiple criteria environment: A case using the AHP in software selection. Eur. J. Oper. Res., 137: 134-144. DOI: $10.1016 / \mathrm{S} 0377-2217(01) 00084-4$

Lhomme, J., J. Humbert and G. Farges, 2013. Nouvelle méthode pour l'analyse de la criticité des dispositifs médicaux en exploitation (MACE). IRBM News, 34: 150-154. DOI: 10.1016/j.irbmnw.2013.08.005

Mummolo, G., L. Ranieri, V. Bevilacqua and P. Galli, 2007. A fuzzy approach for medical equipment replacement planning. Proceedings of the 3rd International Conference Maintenance Facil Management, (MFM' 07), pp: 229-235.

Murali, P., V.D. Reddy and A.N. Phaneendra, 2014. Supplier selection by using multi criteria decision making methods. Int. J. Eng. Res. Gen. Sci., 2: 533-539.

Peniwati, K., 2007. Criteria for evaluating group decision-making methods. Math. Comput. Model., 46: 935-947. DOI; 10.1016/j.mcm.2007.03.005

Podvezko, V., 2011. The comparative analysis of MCDA methods SAW and COPRAS. Eng. Econ., 22: 134-146. DOI: 10.5755/j01.ee.22.2.310

Saaty, T.L. and L.T. Tran, 2007. On the invalidity of fuzzifying numerical judgments in the Analytic Hierarchy Process. Math. Comput. Model., 46: 962-975. DOI: 10.1016/j.mcm.2007.03.022

Saaty, T.L., 2008. Decision making with the analytic hierarchy process. Int. J. Serv. Sci., 1: 83-98. DOI: $10.1504 /$ ijssci.2008.017590

Taghipour, S., D. Banjevic and A.K.S. Jardine, 2011. Prioritization of medical equipment for maintenance decisions. J. Oper. Res. Soc., 62: 1666-1687. DOI: 10.1057 /jors.2010.106 
Taha, Z. and S. Rostam, 2012. A hybrid fuzzy AHPPROMETHEE decision support system for machine tool selection in flexible manufacturing cell. J. Intell. Manuf., 23: 2137-2149. DOI: $10.1007 / \mathrm{s} 10845-011-0560-2$

Tawfik, B., B.K. Ouda and Y.M.A. El Samad, 2013. A fuzzy logic model for medical equipment risk classification. J. Clin. Eng., 38: 185-190. DOI: 10.1097/JCE.0b013e3182a90445

Triantaphyllou, E., B. Shu, S.N. Sanchez and T. Ray, 1998. Multi-criteria decision making: An operations research approach. Encycl. Electr. Electron Eng., 15: $175-186$.

Velasquez, M. and P.T. Hester, 2013. An analysis of multi-criteria decision making methods. Int. J. Oper. Res., 10: 56-66.

Wallsten, T.S., D.V. Budescu, I. Erev and A. Diederich, 1997. Evaluating and combining subjective probability estimates. J. Behav. Dec. Mak., 10: 243-268.

DOI:

10.1002/(SICI)10990771(199709)10:3<243::AID-BDM268>3.0.CO;2-M
Wang, B. and A. Levenson, 2000. PEER REVIEW PAPER: Equipment inclusion criteria-a new interpretation of JCAHO's medical equipment management standard. J. Clin. Eng., 25: 26-26. DOI: 10.1097/00004669-200025010-00009

Wang, B. and W.P. Rice, 2003. JCAHO's equipment inclusion criteria revisited-application of statistical sampling technique. J. Clin. Eng., 28: 37-48. DOI: $10.1097 / 00004669-200301000-00038$

Wang, B., 2012. Medical equipment maintenance: Management and oversight. Synth. Lect. Biomed. Eng., 7: 1-85. DOI: 10.2200/S00450ED1V01Y201209BME045

Youssef, N.F. and W.A. Hyman, 2009. A medical device complexity model: A new approach to medical equipment management. J. Clin. Eng., 34: 94-98. DOI: 10.1097/JCE.0b013e31819fd711

Zardari, N.H., K. Ahmed, S.M. Shirazi and Y.Z. Bin, 2014. Weighting Methods and Their Effects on Multi-Criteria Decision Making Model Outcomes in Water Resources Management. 1st Edn., Springer, Cham, ISBN-10: 3319125869, pp: 166. 